\title{
UPDATING THE NOMOGRAPHICAL DIAGRAMS FOR DIMENSIONING THE BEAMS
}

\author{
Maria T. POP ${ }^{1, *}$ \\ ${ }^{1}$ Faculty of Constructions Cadastru and Architecture, University of Oradea, Str. B. St. Delavrancea nr. \\ 4, Oradea, Judetul Bihor, Romania. \\ corresponding author: mapop@uoradea.ro, +40-7-4466-8245.
}

\begin{abstract}
In order to reduce the time period needed for structures design it is strongly recommended to use nomographical diagrams. The base for formation and updating the nomographical diagrams, stands on the charts presented by different technical publications. The updated charts use the same algorithm and calculation elements as the former diagrams in accordance to the latest prescriptions and European standards. The result consists in a chart, having the same properties, similar with the nomogragraphical diagrams already in us. As a general conclusion, even in our days, the nomographical diagrams are very easy to use. Taking into consideration the value of the moment it's easy to find out the necessary reinforcement area and vice-verse, having the reinforcement area you can find out the capable moment. It still remains a useful opportunity for pre-sizing and designs the reinforced concrete sections.
\end{abstract}

\section{Keywords:}

Bending moment;

Value;

Index;

Chart;

Solution.

\section{Introduction}

In order to reduce the time period needed for structures design it is strongly recommended to use nomographical diagrams.

The base for updating the nomographical diagrams using a computer designing program lays on the charts presented by the volume: "The Design of Reinforced Concrete", authors: Igor Tertea, Traian Oneţ, Marieta Beuran, Vasile Păcurar; Didactic and Pedagogic Publishing House, Bucharest, 1984.

In respect of European Technical Regulations SR EN 1991-1 for concrete structures we have formed nomogram for beams in normal sections. formulas:

The basis for drawing the graphic nomogram was the transposition in charts of the following

$M_{e d}$ is obtained with formula:

$\mu=\frac{M_{E d s}}{b \cdot d^{2} \cdot f_{c d}} \leq \mu_{l i m}$.

The simple reinforcement is used if $\mu \leq \mu_{\text {lim }}$, the reinforcement area being calculated with the following formula:

$A_{s}=\omega \cdot b \cdot d \frac{f_{c d}}{f_{y d}} \pm \frac{N_{E d}}{f_{y d}}$

where:

$\omega=\lambda \cdot \mu \cdot \xi$

$\xi=\frac{\omega}{\lambda \cdot \mu}$

Coefficients $\xi$ and $\omega$ are determined considering $\mu$ from the table 3.5a [3] for concretes $\leq \mathrm{C} 60 / 75$ and $3.5 \mathrm{~b}[3]$ for concretes $>\mathrm{C} 60 / 75$ whatever the steel quality is. 
The coefficients rate $\xi_{\lim }$ and $\mu_{\text {lim }}$ depending of concrete class and for steel S500 are to be found in table 3.3 in [3].

Additional we presented the values of $\xi_{\lim }$ and $\mu_{\text {lim }}$ for concretes up to class C50/60.

OB 37

$P C 52$

$P C 60$

STNB

$$
\begin{aligned}
& \xi_{\lim }=0.769 ; \mu_{\lim }=0.425, \\
& \xi_{\lim }=0.700 ; \mu_{l i m}=0.403, \\
& \xi_{\lim }=0.665 ; \mu_{\text {lim }}=0.390, \\
& \xi_{\lim }=0.647 ; \mu_{\text {lim }}=0.383 .
\end{aligned}
$$

Fig. 1 shows how to use the diagram for a C16 / 20 concrete section, reinforced with PC52

The black color represents the chart for beams sections starting with $200 \times 400(\mathrm{~mm})$ up to $400 \times 800(\mathrm{~mm})$.

\section{Nomographical chart used for designing beams in cross sections} elements.

The use of high class concrete offers an increased safety to elements these are made of

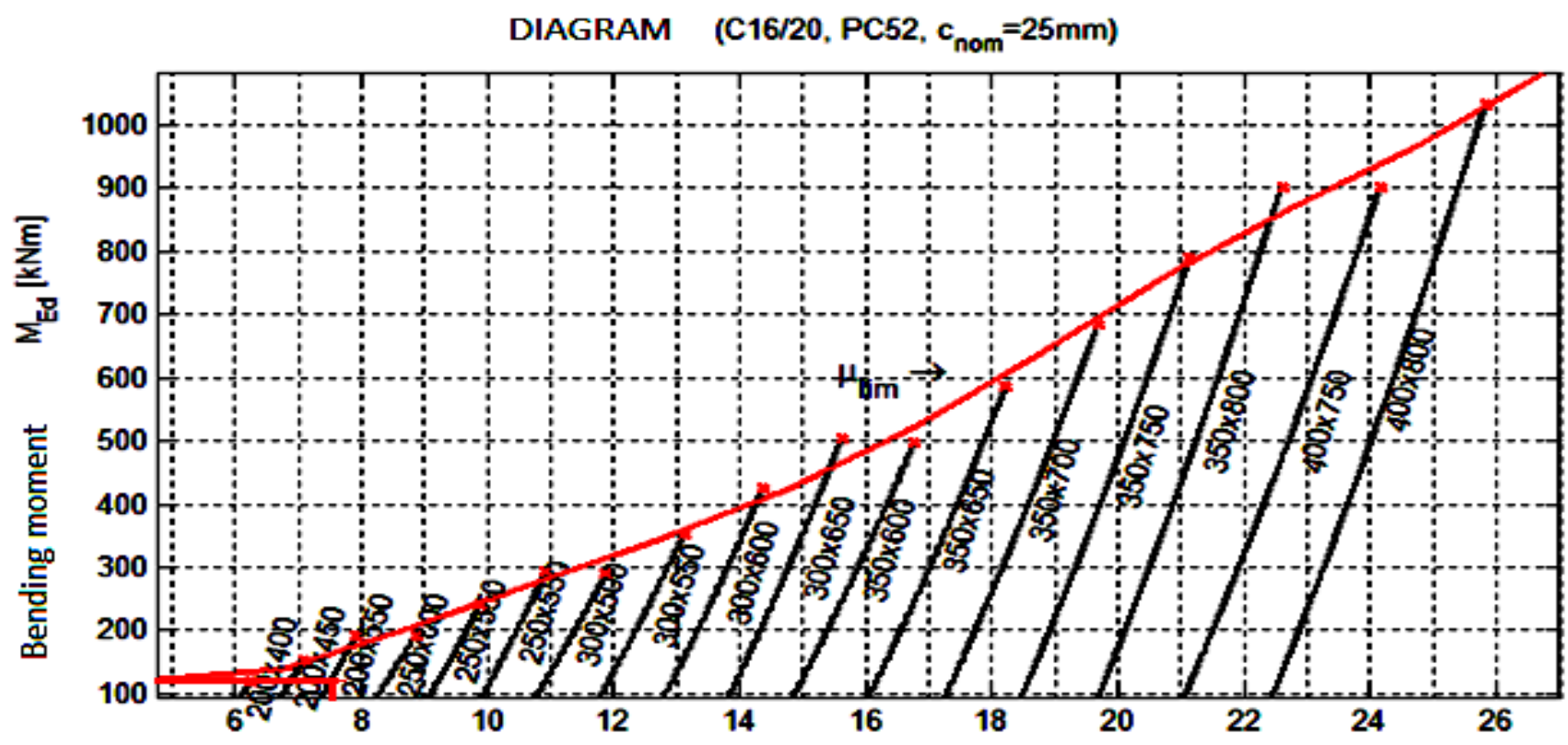

Fig. 1: Nomographical Diagram for $\mathrm{C} 16 / 20$ reinforced concrete beams; Reinforcemt area $A_{s, \text { nec }} \times 10^{2}\left[\mathrm{~mm}^{2}\right]$.

It can be considered either an example of using high class concrete materials in designing reinforced concrete structural elements. For having a comparison, we showed down a new Diagram Fig. 1 and an old one (issued in accordance with the former structural designing rules) presented in the book: "The Design of Reinforced Concrete", authors: Igor Tertea, Traian Oneţ, Marieta Beuran, Vasile Păcurar; Didactic and Pedagogic Publishing House, Bucharest, 1984, for the corresponding concrete class and reinforcement steel, having compatible beam cross sections. 
Heavy or light concrete $B C 20 \mathrm{RC}=12,5 \mathrm{~N} / \mathrm{mm}^{2}$

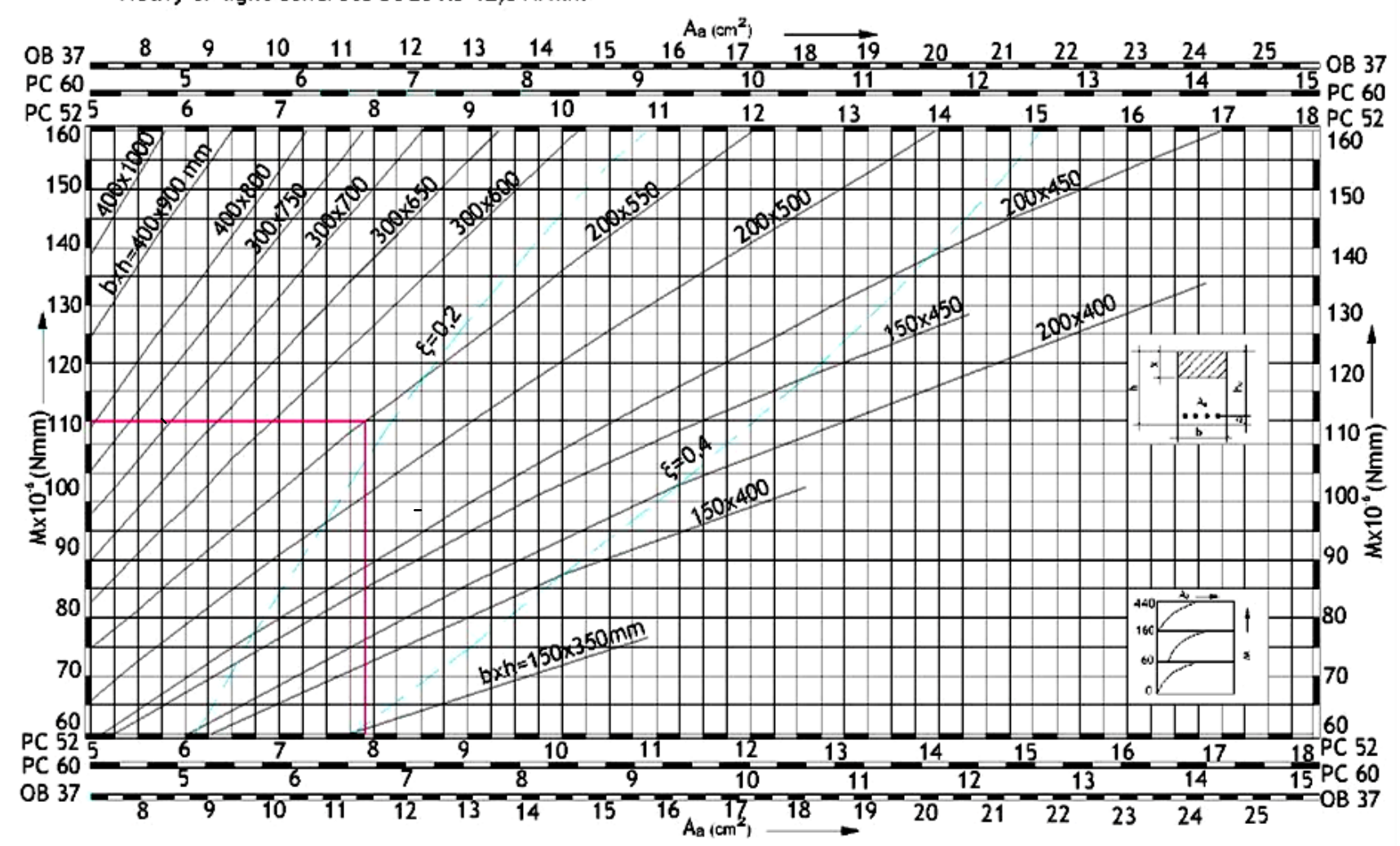

Fig. 2: Nomographical Diagram for design of reinforced concrete beams.

\section{Example}

As an example we chose a beam with cross section $200 \times 550 \mathrm{~mm}$, reinforced with PC 52 steel, having the reinforcement area $790 \mathrm{~mm}^{2}$, having a correspondent to a $110 \mathrm{kNm}$ value of bending moment (see Fig 2). In Fig. 1 the same example for a diagram issued in accordance with SR EN 19911.

In the old diagram the relation exposed in the chart is as follows:

$M \leq A_{a} \cdot R_{a} \cdot\left(h_{0}-a^{\prime}\right)=790 \cdot 290 \cdot(524-26)=114.0 \cdot 10^{-6} \mathrm{Nmm}$.

For a cross section beam $200 \times 550 \mathrm{~mm}$, Bc 20 class concrete, for a $790 \mathrm{~mm}^{2}$ it results a bending moment of $114 \cdot \mathrm{kNm}$. Going on the diagram the bending moment value is $110 \cdot \mathrm{kNm}$.

In the new Diagram, for a $200 \times 550 \mathrm{~mm}$ cross section beam, C 16/20 concrete class, reinforced with PC 52 steel, $790 \mathrm{~mm}^{2}$ reinforcement area, results a bending moment of $110 \mathrm{kNm}\left(110 \cdot 10^{6} \mathrm{Nmm}\right)$.

$f_{y k}=345 \mathrm{~N} \cdot \mathrm{mm}^{-2}$

$E_{s}=210000 \mathrm{~N} \cdot \mathrm{mm}^{-2}$,

$f_{y d}=\frac{f_{y k}}{\gamma_{s}}=\frac{345}{1.15}=300 \mathrm{~N} . \mathrm{mm}^{-2}$,

$f_{c d}=\frac{a_{c c} \cdot f_{c k}}{\gamma_{c}}=\frac{1.0 \cdot 16}{1.5}=10.66 \mathrm{~N} . \mathrm{mm}^{-2}$,

$\varepsilon_{y d}=1000 \frac{f_{y d}}{E_{s}}=1000 \frac{300}{210000}=1.42 \%$. 
Considering the cross section's geometrical characteristics results:

$d_{s}=c+\emptyset / 2=25+22 / 2=36 \mathrm{~mm}$,

$d=h-d_{s}=550-36=514 m m$.

We chose $x=120 \mathrm{~mm}$ for $\varepsilon_{c}=\varepsilon_{c u 2}=3,5 \%$ results the specific deformation in stretched reinforcement:

$\varepsilon_{s}=\varepsilon_{c u 2} \frac{d-x}{x}=3.5 \frac{514-120}{120}=11.49 \%$.

This value $>\varepsilon_{y d}=1.42 \%$.

$\varepsilon_{s}=11.49 \%>\varepsilon_{y d}=1.42 \%$,

The reinforcement reaches the flowing point, so: $\sigma_{s}=f_{y d}$.

For $\varepsilon_{c}=\varepsilon_{c u 2}=3.5 \%$ results $a_{f}=0.81$ (Fig.14.11a) [1].

$F_{c}=b \cdot x \cdot\left(a_{f} \cdot f_{c d}\right)=200 \cdot 120 \cdot(0.81 \cdot 10.66)=207.2 \mathrm{kN}$,

$F_{s}=A_{s} \cdot f_{y d}=790.300=237.0 \mathrm{kN}$,

$F_{s}>F_{c}$, so $x$ is the correct choice.

In Fig. 14.11a [1] for $\varepsilon_{c}=\varepsilon_{c u 2}=3.5 \%$ results $\delta_{x}=0.415$.

$d_{c}=\delta_{x} \cdot x=0.415 \cdot 120=49.8 \mathrm{~mm}$,

$z=d-d_{c}=514-49.8=464.8 \mathrm{~mm}$,

$M_{R d}=F_{s} \cdot z=237.10^{3} \cdot 464.2=110.0 \mathrm{kNm}$.

Another example of the same section, another value of the bending moment.

Now, passing to the formula presented in the chart:

$M_{E d}=\mu \cdot b \cdot d^{2} \cdot f_{e d}=0.403 \cdot 200 \cdot 514^{2} \cdot 10.66=227 \mathrm{kNm}$,

$A_{s}=\omega \cdot b \cdot d \cdot \frac{f_{c d}}{f_{y d}}=\lambda \cdot \mu \cdot \xi \cdot b \cdot d \cdot \frac{f_{c d}}{f_{y d}}=$

$0.8 \cdot 0.4$ é $3 \cdot 0.700 \cdot 200 \cdot 514 \cdot 10.66 / 300=8.24 \mathrm{~cm}^{2}=8.24 \times 10^{2} \mathrm{~mm}^{2}$.

The value of bending moment $M_{E d}$ and the reinforcement area $A_{s}$ can be seen in Fig. 1 chart. It is obvious the conclusion, that in the case of similar beam's geometrical characteristics, using the same reinforcement area, the bearable bending moment (in accordance with SR EN 1991-1) is similar $110 \mathrm{kNm}$

\section{Conclusions}

Charts used for predimensioning and dimensioning of reinforced concrete beams in accordance with SR EN 1992-1, reveals us the utility of using superior concrete classes. The higher concrete classes are to be used. 
Another observation is related with the relative small values of the bending moments for which have been drawn the old diagrams: $60 \mathrm{kNm}-160 \mathrm{kNm}$. The new one contains values within: $(100 \mathrm{kNm}-1000 \mathrm{kNm})$. Because of these differences it was impossible to perform more comparisons. The nomographical diagrams for beams have been drawn using Mathcad 15 program.

\section{References}

[1] CADAR, I. - CLIPI, T. - TUDOR, A.: Renforced Concrete, Edition I, Universitary Horizonts Publishing House, Timişoara, 1999.

[2] CADAR, I. - CLIPI, T. - TUDOR, A.: Renforced Concrete, Edition II, Universitary Horizonts Publishing House, Timişoara, 2004.

[3] KISS, Z . - ONET, T.: Design of Reinforced Concrete Under SR EN 1992-1, Abel Publishing House, Cluj - Napoca, 2008.

[4] TERTEA, I. - ONET, T. - PĂCURAR, V.: The Design Of Reinforced Concrete, Didactic and Pedagogic Publishing House, Bucharest, 1984.

[5] STAS 10107/0-90, Romanian Standards, Civil and Industrial Constructions, Calculation and Composition for Structural Elements Made of Concrete, Reinforced and Prestressed Concrete. 